\title{
Evaluation of Hemodialysis and Hemoperfusion in Poisoned Patients
}

\author{
(D) Bülent Güngörer ${ }^{1}$, (1) Celal Katı², (1) Fulya Köse ${ }^{1}$ \\ ${ }^{1}$ Clinic of Emergency Medicine, Karaman State Hospital, Karaman, Turkey \\ 2Department of Emergency Medicine, Ondokuz Mayıs University Faculty of Medicine, Samsun, Turkey
}

\begin{abstract}
Aim: The aim of our study was to evaluate the demographic data, type of toxic substance, Glasgow Coma scale (GCS), Poisoning Severity score (PSS) and the prognosis of the patients who were admitted to the emergency department (ED) with a preliminary diagnosis of acute intoxication and then underwent hemodialysis (HD) or hemoperfusion (HP), and to compare this data with other studies.

Materials and Methods: The study retrospectively analyzed the files of 36 poisoned patients who were admitted to the ED and who underwent HD or HP by using the hospital electronic data system.

Results: HD was administered to 27 patients (75.0\%) and HP was administered to nine patients (25.0\%). Among the patients treated with HD, five (18.5\%) were poisoned by valproic acid, one (3.7\%) by amlodipine, one (3.7\%) by organic phosphorus, one (3.7\%) by paracetamol, four (14.8\%) by mushroom, two (7.4\%) by ethyl alcohol/ethanol, three (11.2\%) by lithium and ten (37.0\%) by methyl alcohol/methanol. Among the patients treated with HP, one (11.1\%) was poisoned by organic phosphorus, seven (77.8\%) by amitriptyline, and one (11.1\%) by phenytoin. The median GCS score was 10, and the median PSS was 3. The deceased patients had significantly lower GCS scores while their PSS was significantly higher. Eleven patients died, and 25 patients were discharged with full recovery.

Conclusion: This is a multifaceted study that investigated poisoned patients treated with HD or HP and presented treatment modalities that are currently used, and we think they will be used more widely in the future.
\end{abstract}

Keywords: Hemodialysis, hemoperfusion, poisoned, prognosis

\section{Introduction}

Substances that disrupt the vital functions of the organism when a certain amount enters the body are called toxic substances. When such substances harm the body, it is called intoxication. Poisoning cases are quite common all over the world. In the United States, more than 5 million people are being treated due to exposure to biological or chemical agents each year. According to descriptive research data from the studies in Turkey, acute intoxication cases that applied to emergency departments (ED) are 0.3-5\% among all the applications to the ED. Pesticides, cleaning products and carbon monoxide intoxications are observed in decreasing frequency, respectively. Analgesics constitute the majority of the medications that cause acute intoxication, and this is followed by sedative-hypnotics and antidepressants, respectively (1).

After stabilization of the patient, the purpose of the treatment is to apply procedures towards the poison. The general approach to toxic exposure cases involves keeping away the patient from the substance and removing the substance from the patient. Extracorporeal treatments (ECTR) are used to remove toxic substances from the body of intoxicated patients. ECTR methods include dialysis [hemodialysis (HD), modified forms of HD, and peritoneal dialysis], hemoperfusion (HP), exchange transfusion, and plasmapheresis. Today, ECTRs are mostly used for methanol, ethylene glycol, lithium, salicylate, and phenobarbital poisoning (2-4). 
HD is mainly based on diffusion. There is an exchange of solutes between the blood and the dialysate separated by the membrane (5). HP refers to the process by that the blood is passed through a cartridge containing activated charcoal or carbon (6).

The aim of the our study was to evaluate the demographic data, type of toxic substance, Glasgow Coma scale (GCS), Poisoning Severity score (PSS) and the prognosis of the patients who were admitted to the ED with a preliminary diagnosis of acute intoxication and then underwent HD or HP, and to compare this data with other studies.

\section{Materials and Methods}

Between January 2006 and December 2013, 5, 998 acute poisoning cases were admitted to the ED of Ondokuz Mayıs University Hospital, and 40 of them underwent HD or HP. This study retrospectively examined the files of 40 poisoned patients who underwent HD or HP. Three patients were excluded from the study due to multiple drug intake and one patient due to multiple drug intake and chronic kidney failure. Patients aged less than 18 years were also excluded from the study. The study was approved by the Clinical Research Ethics Committee of Ondokuz Mayıs University (OMU KAEK resolution no: 2014/853).

The following data were retrieved from the patient files and the hospital electronic data system: Name, surname, age, gender, the history of previous systemic disease and suicide attempt, the cause of intoxication (drinking medicines or pesticides, eating mushrooms, and methanol or ethanol intake), GCS and PSS at admission and the outcome (death or discharge with full recovery). The degree of intoxication was rated according to the GCS and PSS at the time of admission.

PSS was applied to the most severe symptomatology. Severity grades of PSS were described as:

None (grade 0): No symptoms or signs related to poisoning,

Minor (grade 1): Mild, transient, and spontaneously resolving symptoms,

Moderate (grade 2): Pronounced or prolonged symptoms,

Severe (grade 3): Severe or life-threatening symptoms,

Fatal (grade 4): Death.

Nephrology consultation notes were available in all patient files and the indications for HD or HP were grouped as follows:

- to enhance the elimination of toxins,

- the development of acute kidney failure during the follow-up,
- the development of acute liver failure during the follow-up,

- unresponsive metabolic acidosis and altered states of consciousness despite supportive care.

\section{Statistical Analysis}

The data were analyzed using IBM SPSS statistical software (version 22.0, SPSS, Inc., Chicago, IL). The descriptive statistics were presented as mean \pm standard deviation, median (minimum-maximum), frequency distribution, and percentage. Additionally, the chi-square test and Fisher's exact test were also used. The normality of variables was examined using histograms, probability graphs, and the tests of normality (the KolmogorovSmirnov test and Shapiro-Wilk test). The Mann-Whitney U test was used to test that of non-normally distributed variables. The level of statistical significance was set at $p<0.05$.

\section{Results}

The mean age of 36 patients was $40.1 \pm 17.9$ years, and the median was 37 (range: 18-80). Twenty patients (55.6\%) were male. The median GCS score was 10 (range: 3-15), and the median PSS was 3 (range: 1-3).

Among the patients admitted to the ED due to poisoning and treated with HD, five (18.5\%) were poisoned by valproic acid, one (3.7\%) by amlodipine, one (3.7\%) by organic phosphorus, one (3.7\%) by paracetamol, four (14.8\%) by mushroom, two (7.4\%) by ethanol, three (11.2\%) by lithium, and ten (37.0\%) by methanol. Among the patients treated with HP, one (11.1\%) was poisoned by organic phosphorus, seven (77.8\%) by amitriptyline, and one (11.1\%) by phenytoin (Table 1).

Table 1. Distribution of hemodialysis/hemoperfusion among the patients

\begin{tabular}{lllll}
\hline & \multicolumn{2}{l}{ Treatment } \\
\cline { 2 - 5 } & \multicolumn{2}{l}{ Hemodialysis } & \multicolumn{2}{l}{ Hemoperfusion } \\
\cline { 2 - 5 } & $\mathbf{n}$ & $\%$ & $\mathbf{n}$ & $\%$ \\
\hline Valproic acid & 5 & 18.5 & 0 & 0 \\
\hline Amlodipine & 1 & 3.7 & 0 & 0 \\
\hline Organic phosphorus & 1 & 3.7 & 1 & 11.1 \\
\hline Amitriptyline & 0 & 0 & 7 & 77.8 \\
\hline Paracetamol & 1 & 3.7 & 0 & 0 \\
\hline Mushroom & 4 & 14.8 & 0 & 0 \\
\hline Ethanol & 2 & 7.4 & 0 & 0 \\
\hline Lithium & 3 & 11.2 & 0 & 0 \\
\hline Methanol & 10 & 37.0 & 0 & 0 \\
\hline Phenytoin & 0 & 0 & 1 & 11.1 \\
\hline Total & 27 & 100 & 9 & 100 \\
\hline
\end{tabular}


Among the patients treated with $\mathrm{HD}$ or HP to enhance elimination, ten $(35.7 \%)$ were poisoned by methanol, seven (25.0\%) by amitriptyline, five $(17.9 \%)$ by valproic acid, three (10.7\%) by lithium, two (7.1\%) by mushroom, and one (3.6\%) by phenytoin. Among the patients who underwent HD or HP and developed kidney failure during the treatment, one (33.3\%) was poisoned by amlodipine, one (33.4\%) by organic phosphorus, and one (33.3\%) by paracetamol. Among the patients who underwent HD or HP and developed liver failure during the treatment, two (100\%) were poisoned by mushroom. Among the patients who underwent HD or HP due to unresponsive metabolic acidosis and altered states of consciousness despite supportive care during the follow-up, two (66.7\%) were poisoned by ethanol and one (33.3\%) by organic phosphorus (Table 2 ).

The median GCS score at the time of admission was 3 (range: 3-15) for the deceased patients, and 13 (range: 3-15) for the patients discharged with full recovery. This difference was statistically significant $(p=0.011)$.

The median PSS at the time of admission was 3 (range: 3-3) for the deceased patients and 2 (range: 1-3) for the patients discharged with full recovery. This difference was also statistically significant $(p=0.001)$.

Among the patients who were treated with HD or HP to enhance elimination, five (17.8\%) died, and 23 (82.1\%) were discharged with full recovery. Among those treated with HD or HP for other reasons, six (75.0\%) died, and two (25.0\%) were discharged with full recovery. There was a statistically significant difference between the prognosis groups in terms of the indications for administering HD or HP $(p=0.005)$.

Considering the distribution of prognosis, 11 (30.6\%) patients died, and 25 (69.4\%) were discharged with full recovery.

\section{Discussion}

Poisoning cases constitute an essential part of the patients admitted to the ED. Although a limited number of patients need HD or HP in poisoning, these treatments are life-saving when necessary. Although ECTR remain in the background due to clinical deficiency and inefficacy, they are an essential part of toxicology. In our study, 5.998 patients were admitted to the ED due to acute intoxication over a 7-year period, and $40(0.6 \%)$ of them were treated with HD or HP. In the literature, the rate of ECTR in acute intoxications has been reported as $0.1 \%$ (7). In this respect, we think that the number of patients who underwent HD and HP for poisoning was not low compared with the literature.

The male patients composed $55.6 \%$ of the cases. In the multicenter study of Taghaddosinejad et al. (8), the male patients composed $57 \%$ of the cases.

Taghaddosinejad et al. (8) and Lund et al. (9), who studied 1.065 cases, reported that the incidence of poisoning had its peak in the third decade of life. We think that the main reason why there is no significant difference in age distributions in our study is the low number of cases.

In our study, 27 (75.0\%) patients underwent HD and nine (25.0\%) underwent HP. Methanol poisoning consituted the largest group with ten patients, which was followed by amitriptyline poisoning with seven patients. Mardini et al. (10) reviewed all cases that underwent ECTR and reported that 294 (61.0\%) cases underwent HD, and 52 (12.2\%) underwent HP during the period from 2010 to 2014. During that period, the majority of patients who underwent ECTR consisted of cases of metformin poisoning, which were followed by cases of methanol poisoning. During the period from 2000 to 2009, the majority of patients

Table 2. Distribution of hemoperfusion/hemodialysis treatment indications

\begin{tabular}{lllll}
\hline & \multicolumn{2}{l}{ The indications of hemoperfusion/hemodialysis } & \\
\cline { 2 - 4 } & Enhance elimination (\%) & Kidney failure (\%) & Liver failure (\%) & $\begin{array}{l}\text { Metabolic acidosis and altered } \\
\text { states of consciousness (\%) }\end{array}$ \\
\hline Valproic acid & $5(17.8)$ & 0 & 0 & 0 \\
\hline Amlodipine & 0 & $1(33.3)$ & 0 & 0 \\
\hline Organic phosphorus & 0 & $1(33.4)$ & 0 & $1(33.3)$ \\
\hline Amitriptyline & $7(25.0)$ & 0 & 0 & 0 \\
\hline Paracetamol & 0 & $1(33.3)$ & 0 & 0 \\
\hline Mushroom & $2(7.1)$ & 0 & $2(100)$ & $2(66.7)$ \\
\hline Ethanol & 0 & 0 & 0 & 0 \\
\hline Lithium & $3(10.7)$ & 0 & 0 & 0 \\
\hline Methanol & $10(35.7)$ & 0 & 0 & 0 \\
\hline Phenytoin & $1(3.6)$ & 0 & 0 & 3 \\
\hline Total & 28 & 3 & 2 & 0 \\
\hline
\end{tabular}


who underwent ECTR consisted of cases of methanol poisoning. In their study, among all ECTR cases, 51.7\% underwent HD, and 25.7\% underwent HP, while the percentage of HD compared to other techniques increased steadily every year. Compared to their data of the period from 2010 to 2014, the reason that HP had a high percentage in our study was that HP was used for the treatment of amitriptyline poisoning, which composed the second largest group of our cases. However, Mardini et al. (10) reported that ECTR was used in none of the amitriptyline poisoning cases after 1990.

In their multicenter study, Darracq and Cantrell. (11) found that among 90 pediatric and adolescent poisoning cases, ECTR was performed in 78 (86.6\%) cases for enhanced elimination, in 12 (13.3\%) cases due to the development of kidney failure, and in three (3.3\%) cases due to unclear indications. In our study, the reasons for administering HD or HP were as follows: 28 (7.7\%) patients were administered HD or HP to enhance elimination, three (8.4\%) developed renal failure, two (5.5\%) developed liver failure, and three (8.4\%) had unresponsive metabolic acidosis and an altered state of consciousness despite supportive care. In agreement with the finding of Darracq and Cantrell (11), the most frequent indication was also enhanced elimination in our study. Additionally, we observed that HD or HP performed for enhanced elimination compared to other indications led to a better prognosis in terms of survival outcomes. The mortality rate was $17.8 \%$ in the use of HD or HP for enhanced elimination, while it was $75 \%$ in the use of HD or HP for other reasons or indications. No previous study has evaluated prognosis in terms of indications for the use of HD or HP. Therefore, more research is needed to make correct interpretations.

We evaluated the patients according to their GCS score and PSS at the time of admission. The median GCS score at admission was 10 , and the median PSS was 3. Concerning prognosis, the median GCS and the median PSS were 3 in the deceased patients, while they were 13 and 2 , respectively, in the discharged patients. This finding match those observed in earlier studies. In the study by Churi et al. (12), the mean GCS was $12.7 \pm 2.4$, and the mean PSS was $1.5 \pm 0.7$ in 212 severe poisoning cases in India. In the same study, the mean GCS was $6.2 \pm 1.3$, and the mean PSS was $4.0 \pm 0.0$ in the deceased group, while the mean GCS was $13.4 \pm 1.8$ and the mean PSS was $1.5 \pm 0.3$ in the discharged group. In their study involving 71 organophosphate and carbamate poisoning patients in India, Sam et al. (13) reported that the mean GCS was 6.6 6 3.6 in the deceased cases and 10.8 \pm 3.6 in the discharged cases and the difference was significant. In their study, the mean PSS was $4.0 \pm 0$ in the deceased cases and $2.5 \pm 0.7$ in the discharged cases. Consistent with the literature, we found that the lower the GSC and the higher the PSS were at the time of admission, the higher the mortality rate.

In our study, all 36 patients were monitored in the intensive care unit (ICU), and 30.6\% had a mortal course. In Taghaddosinejad et al. (8), $17.7 \%$ of 175 patients monitored in the ICU died. The mortality rate was lower in some other studies $(13,14)$. The mortality rate in our study was quite high compared to those reported in earlier studies. A possible explanation for this might be that the study population consisted of critical patients undergoing HD or HP. This result may also be explained by the fact that this study was conducted in a regional reference hospital and included only severe poisoning cases.

\section{Study Limitations}

The most important limitation of this study was the small number of patients.

\section{Conclusion}

Consequently, this study serves as a preliminary study that has investigated intoxicated patients that were treated with HD or HP in a multifaceted manner and presented treatment modalities that are currently being used and that we think that will be used more widely in the future. Since similar studies do not exist in our country, we can say that our study is essential in terms of shedding light on the studies to be carried out from now on.

\section{Ethics}

Ethics Committee Approval: The study was approved by the Clinical Research Ethics Committee of Ondokuz Mayıs University (OMU KAEK Resolution no: 2014/853).

Informed Consent: This is a retrospective study in which patients' identity information is not used.

Peer-review: Externally and internally peer-reviewed.

\section{Author Contributions}

Concept: B.G., C.K., F.K., Design: B.G., C.K., F.K., Data Collection or Processing: B.G., C.K., F.K., Analysis or Interpretation: B.G., C.K., F.K., Literature Search: B.G., C.K., F.K., Writing: B.G., C.K., F.K.

Conflict of Interest: No conflict of interest was declared by the authors.

Financial Disclosure: The authors declared that this study received no financial support.

\section{References}

1. Denizbașı A. Zehirlenmiș Hastaya Acil Yaklaşım. In: Kekeç Z, editor. Tüm Yönleriyle Acil Tıp Tanı Tedavi ve Uygulama Kitabı. 2. Baskı. Adana: Nobel Kitabevi ; 2011.p.421-430. 
2. Balal M. Zehirlenmelerde Ekstrakorporal Tedavi Yöntemleri. In: Satar S, editor. Acilde Klinik Toksikoloji. Adana: Adana Nobel Kitabevi; 2009.p.101-11.

3. Poyrazoğlu MH, Gürgöze MK, Akyıldız BN, Dursun I. Dialysis Methods in Poisoning Treatment. Turkiye Klinikleri J Pediatr Sci. 2006;2:11-5.

4. Holubek WJ, Hoffman RS, Goldfarb DS, Nelson LS. Use of hemodialysis and hemoperfusion in poisoned patients, Kidney Int. 2008;74:1327-34.

5. Selçuk Y. Hemodiyaliz. In: Şindel Ş, editor. Nefroloji ve Hipertansiyon Tanı ve Tedavi: Birinci baskı. Ankara: Ayrıntı basımevi; 2012.p.437-43.

6. de Pont AC. Extracorporeal treatment of intoxications. Curr Opin Crit Care. 2007;13:668-73.

7. Mowry JB, Spyker DA, Cantilena LR Jr, Bailey JE, Ford M. 2012 Annual Report of the American Association of Poison Control Centers' National Poison Data System (NPDS): 30th Annual Report. Clin Toxicol (Phila). 2013;51:949-1229.

8. Taghaddosinejad F, Sheikhazadi A, Yaghmaei A, Mehrpour O, Schwake L. Epidemiology and Treatment of Severe Poisoning in the Intensive Care Unit: 60 Lessons from a One-Year Prospective Observational Study. J Clinic Toxicol S. 2012;007.
9. Lund C, Teige B, Drottning P, Stiksrud B, Rui TO, Lyngra M, et al. A one-year observational study of all hospitalized and fatal acute poisonings in Oslo: Epidemiology, intention and follow-up. BMC Public Health. 2012;12:858.

10. Mardini J, Lavergne V, Roberts D, Ghannoum M. Case report of extracorporeal treatments in poisoning: historical trends. Semin Dial. 2014;27:402-6.

11. Darracq MA, Cantrell FL. Hemodialysis and extracorporeal removal after pediatric and adolescent poisoning reported to a state poison center. J Emerg Med. 2013;44:1101-7.

12. Churi S, Ramesh M, Bhakta K, Chris J. Prospective Assessment of Patterns, Severity and Clinical Outcome of Indian Poisoning Incidents. Chem Pharm Bull (Tokyo). 2012;60:859-64.

13. Sam KG, Kondabolu K, Pati D, Kamath A, Pradeep Kumar G, Rao PG. Poisoning severity score, APACHE II and GCS: Effective clinical indices for estimating severity and predicting outcome of acute organophosphorus and carbamate poisoning. J Forensic Leg Med. 2009;16:239-47.

14. Schwake L, Wollenschlager I, Stremmel W, Encke J. Adverse drug reactions and deliberate self-poisoning as cause of admission to the intensive care unit: a 1-year prospective observational cohort study. Intensive Care Med. 2009;35:266-74. 